\title{
Sensitivity of CNOSSOS-EU sound propagation model to digital surface components
}

\author{
Edina Anna Balogh ${ }^{1, *}$, Tamás Schmelz ${ }^{1}$, László Orosz ${ }^{1}$ \\ ${ }^{1}$ KTI Institute for Transport Sciences, Department for Transport Acoustics, \\ Than Károly utca 3-5, H 1119 Budapest, Hungary \\ *e-mail: balogh.edina@kti.hu
}

Submitted: 22/10/2021 Accepted: 08/01/2022 Published online: 23/02/2022

\begin{abstract}
The accuracy of input data is a key issue in sound propagation model calculations. This paper aimed to assess the effect of building and land cover input data accuracy on CNOSSOS-EU sound propagation model outputs. Calculations were performed for a study site with a quite diverse land cover structure, located along a major road in Monor, Hungary. Nine test cases were defined based on building and land cover datasets with different accuracy. Comparing the results of the test cases to each other, it was found that in residential areas, the sound propagation model is more sensitive to the building data than to the land cover data. Therefore, it is recommended to use more detailed building input data in those areas, while using a land cover database with higher resolution than CORINE land cover data does not provide significantly better results. In non-residential areas, the influence of land cover input data on model results increases significantly.
\end{abstract}

Keywords: strategic noise mapping; CNOSSOS-EU; environmental noise propagation; input data

\section{INTRODUCTION}

According to Environmental Noise Directive 2002/49/EC (END), the first European Directive about strategic noise mapping, EU Member States are required to prepare strategic noise maps and action plans for agglomerations (urbanized areas with more than 100000 inhabitants), and also for major roads, major railways and major airports every five years. Strategic noise maps are required for each transport sector, applying the day-evening-night noise indicator (Lden [dB]: day-evening-night sound level, defined by the formula (1), according to the Annex I of END) and the night-time noise indicator (Lnight $[\mathrm{dB}]$ : night sound level, defined by the description below the formula (1)). Based on the emission values calculated from annual average daily traffic data, the immission values at the receivers are determined by a model calculation describing the sound propagation. To prepare the strategic noise maps, Member States are required to use the new common assessment methods (CNOSSOS-EU method, a harmonised methodological framework for noise assessment, developed through the project "Common NOise aSSessment methOdS in the EU" lead by the Joint Research Centre of the European Commission between 2008-2014 [1]) published in the
Commission Directive (EU) 2015/996 from 1 January 2019.

$$
\begin{aligned}
L_{\text {den }}=10 \lg \frac{1}{24}( & 12 \cdot 10^{\frac{L_{\text {day }}}{10}}+4 \cdot 10^{\frac{L_{\text {evening }}+5}{10}} \\
& \left.+8 \cdot 10^{\frac{L_{\text {night }}+10}{10}}\right)
\end{aligned}
$$

where: Lday, Levening and Lnight are the Aweighted long-term average sound levels $[\mathrm{dB}]$ as defined in ISO 1996-2: 1987 [2], determined over all the day, evening and night periods of a year successively.

To develop the sound propagation model of the CNOSSOS-EU method, three existing sound propagation models (NMPB 2008: "Nouvelle Méthode de Prévision du Bruit des Routes", the French method for road traffic noise prediction [3], HARMONOISE: developed within the frame of the European project "Harmonoise", 2001-2004 [4] and ISO 96131 [5]) were evaluated on the basis of several criteria (namely precision, accuracy, computational speed, flexibility, simplicity, and number of parameters) [6]. The results of the investigation showed that the most complex HARMONOISE model, requires too high calculation time, which makes the model unsuitable for large-scale calculations that are needed to 
prepare strategic noise maps. Furthermore, the flexibility of the HARMONOISE model is presumably not relevant for strategic noise mapping, which is based on yearly-averaged noise indicators. Consequently, the NMPB 2008 model was suggested to be applied in the CNOSSOS-EU method. Examining test cases, another comparative analysis of the above three models gave the result that the HARMONOISE model does not perform better than the two simpler ones [7]. The reason for this may be that the HARMONOISE model is more sensitive to the input data. It was pointed out that it is not expected that the data to be used for strategic noise mapping would be more detailed than now.

The CNOSSOS-EU sound propagation model based on NMPB, is a point-to-point sound propagation method. From the sound emission level at the source, the sound level at the receiver is calculated by subtracting attenuation terms, which represent geometrical attenuation, air absorption, ground attenuation and screening attenuation [8]. Two particular types of atmospheric conditions (favourable and homogeneous) are taken into account. The long-term occurrence of favourable conditions is described by parameter $\mathrm{p}$ with a value of between 0 and 1 [1]. The acoustic absorption of the ground is represented by a dimensionless coefficient $G$ with a value of between 0 and 1 , which is independent of frequency [1].

A number of problems with the CNOSSOS-EU sound propagation model has been identified (e.g. concerning the Rayleigh-criterion and the retrodiffraction [8]) since it was published in Directive 2015/996. In 2018-19 a study was prepared by an EU working group with a view to establish the refining of the COSSOS-EU method, including its sound propagation parts [9] [10]. Based on that study, the amendments were published in Commission Delegated Directive (EU) 2021/1226.

The quality of input data is a key issue for preparing strategic noise maps with sufficient accuracy. As each EU member state can use different sources for input levels, it is difficult to obtain comparable results in spite of the common calculation method [11]. A data guideline would be needed to solve that problem [11], but no instructions have been published so far. Therefore, each member state is responsible for the selection of input data sources.

When selecting the input datasets to be used, availability, cost and required data processing have to be considered. Calculation time is another important issue to be examined for making a decision about the number and the accuracy of parameters taken into account in the model. The required accuracy of the input data should be determined considering the above aspects, besides the strategic level and the scale of the task.
The impact of input data on the outputs of model calculations has been discussed in several articles. Morley et al. assessed the performance of the CNOSSOS-EU road traffic noise prediction model using input data with different resolutions [12]. Six test scenarios were examined from the highest to the lowest resolution dataset. Both input data determining the emission (e.g. traffic flow, speed limits) and those influencing the sound propagation (e.g. land cover, building heights and topography) were analysed. The effect of traffic flow data proved to be the most significant factor in model calculations.

Aballéa et al. investigated the sensitivity of outdoor sound propagation predictions to environmental parameters to suggest different simplified approaches which can be used to reduce the calculation time, providing results that still meet the accuracy requirements [13]. Among other parameters, the ground effect was investigated, comparing cases with various heterogeneity values of ground surface absorption to a case assuming a homogeneous equivalent ground surface. It was stated that the difference in the A-weighted global excess attenuations calculated for the real case and the average ground surface does not exceed $0.3 \mathrm{~dB}$.

Concerning the environmental noise propagation model calculations, the main influencing factors to be taken into account are the following:

- atmospheric absorption (which depends on the distance from the source and the atmospheric conditions);

- topography;

- foliage;

- acoustic characterisation of ground;

- obstacles (e.g. buildings and barriers);

- meteorological conditions (e.g. temperature gradient, wind direction).

The required accuracy of building data is an important issue, because the cost of such databases is quite significant in the implementation of strategic noise mapping tasks. Land cover data which can be used to describe the acoustic absorption properties of the ground is important to be examined, as assigning $G$ values used in CNOSSOS-EU model to various land cover classes provided by different land cover data sources is not obvious. A sensitivity analysis could provide information on the importance of the accuracy of land cover data in sound propagation model calculation.

Several data sources for buildings used in sound propagation model calculations are discussed in the relevant literature, some of which provide data at the international level, while others are only available in a given country. The data model for noise simulation studied by Kumar et al. contains the following data for buildings: class of building, function (residential, public or industrial), usage, year of construction, 
year of demolition, type of the roof, measured height, number of the stories above and below ground and their heights [11]. Morley et al. examined two versions concerning the building height: in the higher resolution version, individual building heights from LiDAR measurements were applied, while in the lower resolution case generalized surface provided by averaging the LiDAR building heights over a $50 \mathrm{~m}$ grid or the constant value of $9.5 \mathrm{~m}$ were used [12]. The Irish guide for CNOSSOS-EU adaptation denotes OSiPRIME 2 product as the possible source of $2 \mathrm{D}$ building data, while building heights are recommended to be derived from LiDAR datasets or based on site surveys on the number of stories or estimated height values [14]. In the examination of the spatial relationship between air pollution and noise caused by traffic in two Danish cities, polygon shapefile of building footprints based on a national dataset (Kort10DK) was used with estimated building heights applying a national elevation model having $1 \mathrm{~m} \times 1 \mathrm{~m}$ resolution [15].

Concerning the acoustic absorption of the ground, Kumar et al. used an attribute to model the degree of noise absorption by the land area with the values of 0 (hard), 0.5 (medium/middle) and 1 (soft) [11]. In the sensitivity analysis of Aballéa et al., two types of ground (reflective and absorbing) modelled by two impedances were taken into account [13]. In the examination performed by Morley et al., the extra detailed OS MasterMap Topography Layer ${ }^{\circledR}(1 \mathrm{~m}$ precision) was used in the higher resolution test cases, while the lower resolution versions were based on the less detailed CORINE 2006v16 database ( 100 m precision) [12]. (The CORINE land cover dataset was developed in the framework of the CORINE - CO-oRdination of INformation on the Environment programme, accepted by the European Commission in 1985.) In Ireland, the following datasets are available: OSiPRIME2 (with a resolution of 1:1 000, 1:2 500, 1:5 000), OSi DigiCity (1:15 000), OSi LiDAR (may not be available in all areas of the country), CORINE (1:100 000) [14]. In the study of Khan et al. on the spatial relationship between traffic-related air pollution and noise, CORINE land cover data (version 2012) with a spatial resolution of $100 \mathrm{~m}$ was applied [15].

The aim of the present study is to examine the effect of the accuracy of building and land cover data on CNOSSOS-EU sound propagation model outputs, comparing results based on different data sources to each other. Road traffic was taken into account as a source, and calculations were performed on datasets from a study site located along a major road. The aim was to provide recommendations on how detailed building and land cover input data are worth using in strategic noise mapping tasks. It was expected that the accuracy of building data is particularly significant in residential areas, while the influence of land cover data may increase in areas with fewer buildings and a more diverse land cover characteristic.

\section{DATA ACQUISITION AND METHODS}

\section{Study area}

The study site shown in Fig. 1 is located in the Municipality of Monor, which is a town in Pest

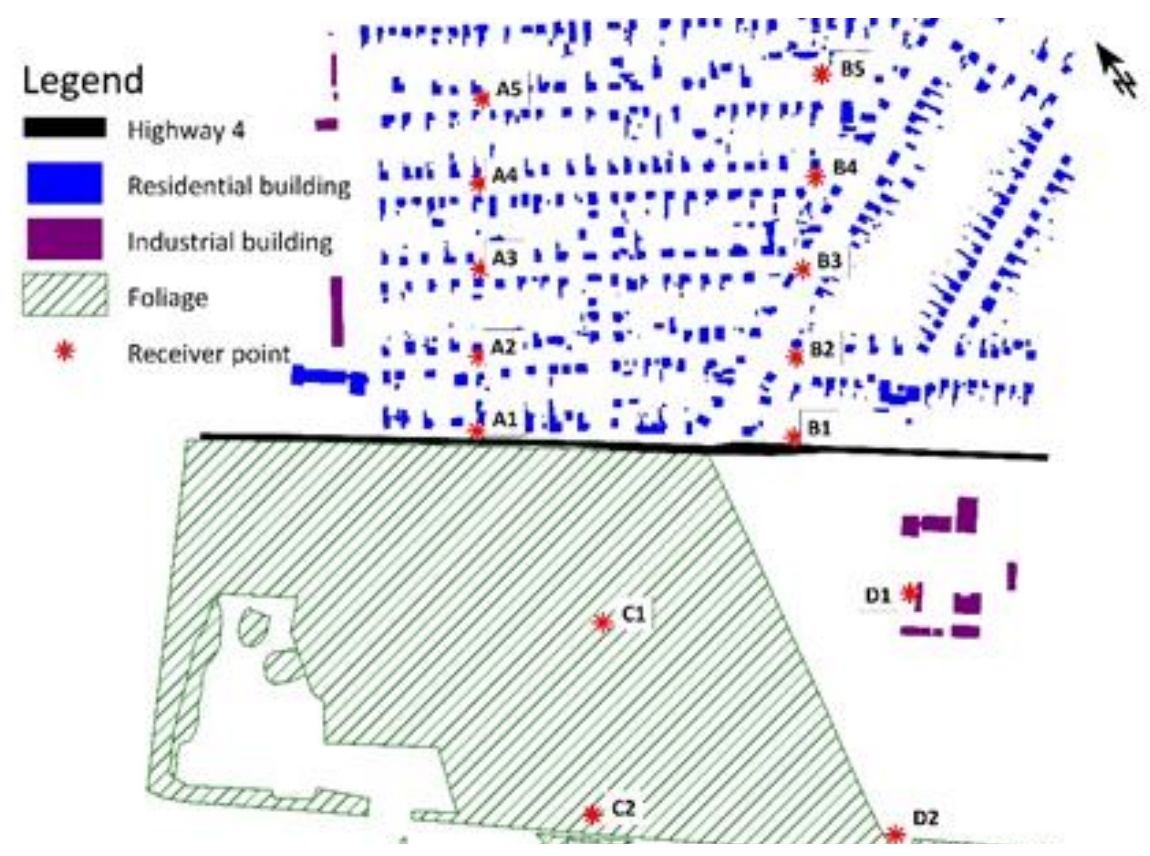

Figure 1. Study site /Sources of data: buildings: Regulatory Plan of Municipality of Monor, www.monor.hu; road geometry and foliage: 2019 orthophotos, Lechner Knowledge Center, www. geoshop.hu/ 
County with a population of 17626 [16]. The study site is crossed by Highway 4, which is a major road according to the $49 / 2002$ EU Directive, as it has more than three million vehicle passages a year on the examined section [17]. The total area of the study site is $0.53 \mathrm{~km} 2$. In site selection, it was a main aspect that the land cover is quite different on the two sides of the area. On the left side of Highway 4, there is a residential area consisting mainly of detached houses, with some shops and restaurants, while on the other side of the road, the area is mainly covered by forest, and there is a small industrial area as well. Another important factor was that several different building data sources and both CORINE and Urban Atlas as land cover databases were available for that area.

\section{Input data}

Some of the input data used in the sound propagation model were available directly, while other data were generated by digitizing different maps or based on on-site surveys.

\section{A. Emission}

Road traffic noise emission was determined applying the CNOSSOS-EU calculation method, based on the 2020 annual average daily traffic flow data [17]. Vehicle categories on which the Hungarian traffic count is based were assigned to the CNOSSOS-EU vehicle classes. The speed limit for all vehicle categories was considered as $50 \mathrm{~km} / \mathrm{h}$ according to the traffic regulation for that given road section.

\section{B. Buildings}

Different data sources were used for the purpose of sensitivity analysis. The data sources and the input data provided by them were the following:

- Regulatory Plan of Municipality of Monor (2010, freely available on the official website of the municipality, www.monor.hu): building footprints (see Fig. 1);

- orthophotos (2019, provided by the Lechner Knowledge Center, www.geoshop.hu): building footprints;

- site survey (July 2021): building heights (reference building heights were measured and the height of the other buildings were established based on the number of levels, roof type and other characteristics e.g. mezzanine-floor), function of buildings (noise sensitive buildings: residential, educational; auxiliary buildings: outbuildings, garages, industrial buildings, shops, restaurants etc.), refined building footprint datasets (e.g. by deleting buildings present in the 2019 orthophotos or the 2010 Regulatory Plan but that no longer exist, recording roofed terraces and carports, which are considered as "floating screens" in model calculation).
Based on these available data sources, three input datasets with different accuracy were composed:

- building footprints based on the Regulatory Plan and estimated building heights, assigning a constant value of $6 \mathrm{~m}$ for each building uniformly (Regulatory Plan, version “a”);

- building footprints based on the Regulatory Plan and building heights based on the results of the site survey (Regulatory Plan, version " $b$ ");

- building footprints based on 2019 orthophotos and building heights based on the results of the site survey (orthophotos).

\section{Land cover}

The different data sources and the provided input data were the following:

- CORINE (2020, version 2020 20u1): land cover classes;

- Urban Atlas (2020, version UA2018_v012): land cover classes;

- orthophotos (2019, provided by the Lechner Knowledge Center, www.geoshop.hu): extra absorbing areas identified in the residential areas (e. g. gravel or asphalt roads and car parks in the yards), where acoustic absorption properties are different from the ones of gardens.

Based on these three data sources, the following input datasets with different accuracy were created:

- CORINE land cover classes to which the suitable $G$ values were assigned, e.g. $G=1$ for classes "Broad-leaved forest" and "Pastures"; $\mathrm{G}=0$ for class "Industrial or commercial units" (CORINE);

- Urban Atlas land cover classes to which the suitable $G$ values were assigned, e.g. $G=1$ for classes "Forests" and "Pastures"; G=0.7 for class "Discontinuous dense urban fabric"; $\mathrm{G}=0$ for class "Other roads and associated land" (Urban Atlas);

- Urban Atlas land cover classes, improved with the extra reflective areas $(\mathrm{G}=0)$, based on the orthophotos (Urban Atlas+).

Land cover classes on the study site according to the different datasets are shown in Fig. 2-3. Note that in Fig. 2-3 orthophotos from 2010 are shown, which are free to publish (source: fentrol.hu, Lechner Knowledge Center), in the model calculation building data based on 2019 orthophotos were used, nevertheless 


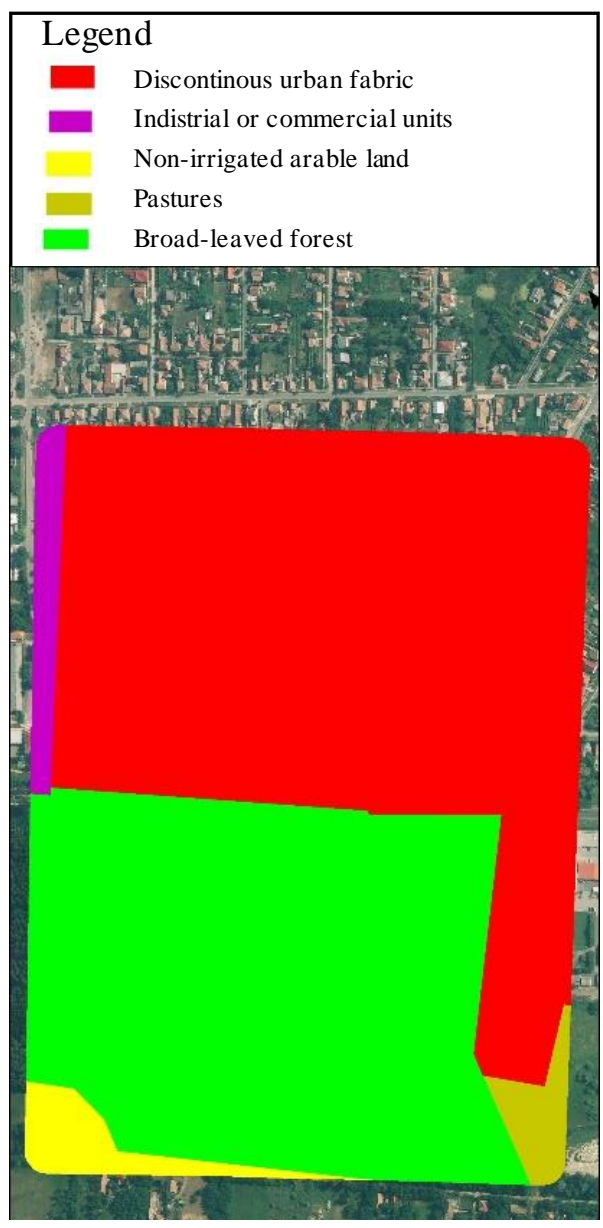

Figure 2. Land cover classes on the study area (CORINE)

\section{Topography}

The digital terrain model (DDM5) is based on contour lines of topographic maps at the scale of 1:10 000 , corrected by stereophotogrammetric evaluation. The dataset was provided by the Lechner Knowledge Center, www.geoshop.hu (downloaded in June 2021).

\section{E. Foliage}

Foliage dataset was generated from 2019 orthophotos (provided by the Lechner Knowledge Center, www.geoshop.hu) with height data evaluated based on site survey (July 2021).

\section{F. Road geometry}

Road geometry data was generated from 2019 orthophotos (provided by the Lechner Knowledge Center, www.geoshop.hu).

\section{G. Meteorological conditions}

As the input data for meteorological conditions were not the subject of the investigation, there was no need for data that describes real conditions accurately. As there is no data available yet in Hungary for parameter $\mathrm{p}$, a value of 0.5 were considered in the model calculation for each part of the day (namely for day, evening and night periods).

\section{Test cases}

Nine test cases were defined based on the building and land cover datasets with different accuracy. The test cases and their abbreviated names are shown in Table 1.

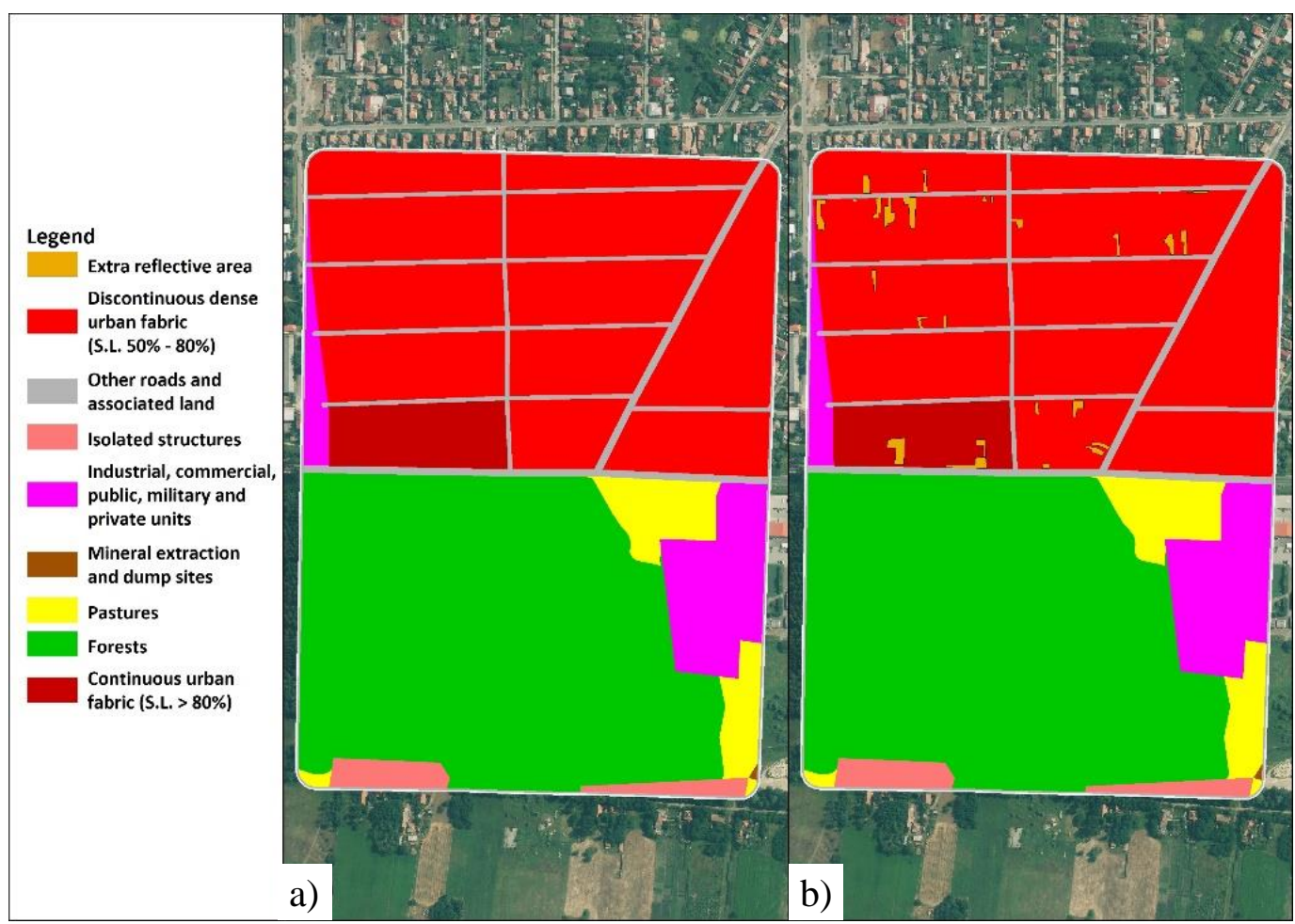

Figure 3. Land cover classes on the study area a) Urban Atlas b) Urban Atlas + 
Table 1. Test cases

\begin{tabular}{|l|c|c|c|}
\hline \multirow{2}{*}{$\begin{array}{c}\text { Building } \\
\text { data source }\end{array}$} & \multicolumn{3}{|c|}{ Land cover data source } \\
\cline { 2 - 4 } & CORINE & $\begin{array}{c}\text { Urban } \\
\text { Atlas }\end{array}$ & $\begin{array}{c}\text { Urban } \\
\text { Atlas+ }\end{array}$ \\
\hline $\begin{array}{l}\text { Regulatory } \\
\text { Plan- } \\
\text { version "a" }\end{array}$ & $\begin{array}{c}\text { RPa- } \\
\text { CORINE }\end{array}$ & RPa-UA & RPa-UA+ \\
\hline $\begin{array}{l}\text { Regulatory } \\
\text { Plan - } \\
\text { version "b" }\end{array}$ & $\begin{array}{c}\text { RPb- } \\
\text { CORINE }\end{array}$ & RPb-UA & RPb - UA+ \\
\hline Orthophotos & $\begin{array}{c}\text { ORTO- } \\
\text { CORINE }\end{array}$ & ORTO-UA & $\begin{array}{c}\text { ORTO- } \\
\text { UA+ }\end{array}$ \\
\hline
\end{tabular}

For the comparison of the performance of each test case, results provided by the ORTO-UA+ test case was considered as the reference value, since it was based on the most detailed building and land cover datasets.

For the same reason, to assess the influence of building input data on the model results, the test cases using building data based on orthophotos were considered as "building reference values". Referring to land cover input data, test cases based on the Urban Atlas+ dataset were regarded as "land cover reference values".

\section{Sound propagation calculation}

Sound propagation calculation was performed using the SoundPLAN software (version 8.2), based on the CNOSSOS-EU Road: 2015 calculation method. 14 receiver points were designated: points A1-A5 and B1-B5 are located in the residential area on the left side of Highway 4, while on the other side, points $\mathrm{C} 1-\mathrm{C} 2$ are found in the forest and points D1D2 were designated in and behind the industrial area (see Fig. 1). At each receiver point, the day-nightevening sound levels (Lden $[\mathrm{dB}]$ ) were calculated at a height of $4 \mathrm{~m}$.

\section{RESULTS AND DISCUSSIONS}

Day-evening-night sound levels (Lden) at each receiver point for the nine test cases are given in Table 2.
At each receiver point, the maximum difference amongst the results for the different test cases (namely the range of Lden values) was calculated (see Fig. 3). In the residential area, the values of maximum differences are quite small at the receiver points close to the source (less than $1 \mathrm{~dB}$ at points A1 and B1). Away from the source, while Lden values decrease, the ranges increase significantly (it exceeds $6 \mathrm{~dB}$ at point $\mathrm{B} 4$ ), as differences between the different data sources exercise their effect more strongly on the longer propagation path. At the furthest receiver points, there are smaller ranges again, as out of the study site there are no buildings and ground effect given in the model; therefore, the propagation conditions are the same for each test case. In the woodland, the differences amongst the test cases are negligible (the range is $0.2 \mathrm{~dB}$ at point $\mathrm{C} 1$ and $0.5 \mathrm{~dB}$ at point $\mathrm{C} 2$ ), as there are no buildings in that area and the land cover input data according to the different sources is quite similar (see Fig. 2). In the industrial area, there is a more significant range in the middle of the propagation path $(3.5 \mathrm{~dB}$ at point D1). This may be partly due to the differences in the input data for buildings. Moreover, the boundaries of land cover classes according to the CORINE and the Urban Atlas databases do not correspond completely either in that area (Fig. 2-3).

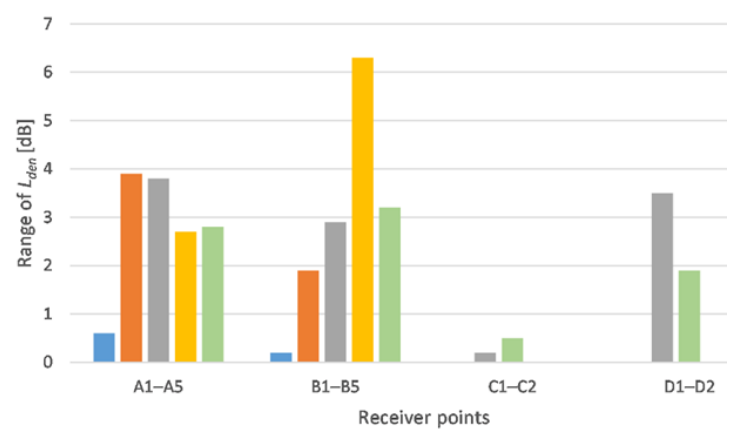

Figure 4. Maximum differences in day-eveningnight sound levels (Lden) in $\mathrm{dB}$ for the test cases at each receiver point

In the next step, the magnitude of the influence on the results was assessed referring to the building and

Table 2. Test cases

\begin{tabular}{|c|c|c|c|c|c|c|c|c|c|}
\hline $\begin{array}{c}\text { Receiver } \\
\text { point }\end{array}$ & $\begin{array}{c}\text { RPa- } \\
\text { CORINE }\end{array}$ & $\begin{array}{c}R P a- \\
\text { UA }\end{array}$ & $\begin{array}{c}R P a- \\
\text { UA+ }\end{array}$ & $\begin{array}{c}\text { RPb- } \\
\text { CORINE }\end{array}$ & $\begin{array}{c}R P b- \\
\text { UA }\end{array}$ & $\begin{array}{c}\text { RPb- } \\
\text { UA+ }\end{array}$ & $\begin{array}{c}\text { ORTHO- } \\
\text { CORINE }\end{array}$ & $\begin{array}{c}\text { ORTHO- } \\
\text { UA }\end{array}$ & $\begin{array}{c}\text { ORTHO- } \\
\text { UA+ }\end{array}$ \\
\hline A1 & 67.4 & 67.6 & 67.7 & 67.1 & 67.3 & 67.3 & 67.1 & 67.3 & 67.3 \\
\hline A2 & 49.3 & 49.9 & 50.5 & 50.3 & 50.9 & 51.4 & 47.5 & 48.0 & 48.6 \\
\hline A3 & 41.9 & 42.3 & 42.4 & 45.2 & 45.5 & 45.7 & 44.8 & 45.2 & 45.3 \\
\hline A4 & 39.8 & 40.1 & 40.1 & 42.1 & 42.5 & 42.5 & 40.7 & 41.2 & 41.3 \\
\hline A5 & 38.6 & 38.9 & 39.1 & 40.8 & 41.2 & 41.4 & 40.3 & 40.7 & 40.9 \\
\hline B1 & 66.8 & 66.9 & 66.9 & 66.8 & 66.9 & 66.9 & 66.9 & 67.0 & 67.0 \\
\hline B2 & 52.0 & 52.3 & 52.3 & 53.0 & 53.3 & 53.3 & 51.4 & 51.8 & 51.9 \\
\hline B3 & 43.8 & 45.2 & 45.3 & 45.7 & 46.7 & 46.7 & 44.6 & 45.6 & 45.6 \\
\hline B4 & 38.4 & 38.8 & 38.8 & 44.0 & 44.5 & 44.5 & 44.3 & 44.7 & 44.7 \\
\hline B5 & 39.3 & 39.7 & 39.8 & 42.0 & 42.4 & 42.5 & 41.2 & 41.6 & 41.6 \\
\hline C1 & 48.2 & 48.2 & 48.2 & 48.1 & 48.2 & 48.2 & 48.0 & 48.1 & 48.1 \\
\hline C2 & 41.9 & 42.1 & 42.1 & 41.9 & 42.1 & 42.1 & 41.6 & 41.8 & 41.9 \\
\hline D1 & 48.8 & 51.1 & 51.1 & 47.6 & 49.9 & 49.9 & 47.7 & 51.0 & 51.0 \\
\hline D2 & 40.8 & 42.0 & 42.0 & 40.6 & 41.7 & 41.7 & 40.1 & 41.0 & 41.0 \\
\hline
\end{tabular}


land cover data. To investigate the importance of input data for buildings, the results of test cases using the same land cover data sources were compared to the corresponding building reference values (results for ORTO-CORINE, ORTO-UA and ORTO-UA+ test cases). Similarly, the analysis of the influence of input data for land cover was based on comparing the results of test cases applying the same building data sources to the suitable land cover reference values (results for RPa-UA+, RPb-UA+ and ORTO-UA+ test cases). To compare the results of test cases to the reference values, two indicators were used at each receiver point: maximum differences from the building/land cover reference values (Table 3 ) and mean of the absolute values of differences from the building/land cover reference values (Table 3 and Fig. 5). Concerning the maximum differences, the signed values are presented, which enables to evaluate the direction of the differences (i. e. whether it is an overestimation or underestimation of the reference value) in addition to their magnitude. On the other hand, when calculating the mean differences, the absolute values of differences were used to represent the average magnitude of the differences at the receiver points in a more appropriate way.

Table 3. Maximum differences and mean of the absolute values of differences from building/land cover reference values in day-evening-night sound levels $\left(L_{d e n}\right)$ in $d B$ at each receiver point

\begin{tabular}{|c|c|c|c|c|}
\hline 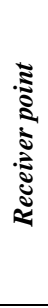 & 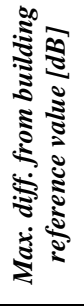 & 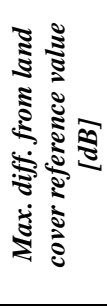 & 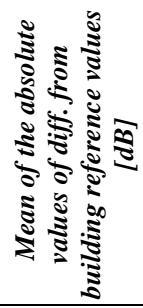 & 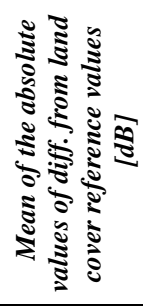 \\
\hline A1 & 0.4 & -0.3 & 0.2 & 0.1 \\
\hline A2 & 2.9 & -1.2 & 2.4 & 0.9 \\
\hline A3 & -2.9 & -0.5 & 1.6 & 0.3 \\
\hline A4 & 1.4 & -0.6 & 1.2 & 0.2 \\
\hline A5 & -1.8 & -0.6 & 1.1 & 0.4 \\
\hline B1 & -0.1 & -0.1 & 0.1 & 0.1 \\
\hline B2 & 1.6 & -0.5 & 1.0 & 0.2 \\
\hline B3 & 1.1 & -1.5 & 0.8 & 0.6 \\
\hline B4 & -5.9 & -0.5 & 3.1 & 0.2 \\
\hline B5 & -1.9 & -0.5 & 1.4 & 0.3 \\
\hline C1 & 0.2 & -0.1 & 0.1 & 0.0 \\
\hline $\mathrm{C} 2$ & 0.3 & -0.3 & 0.1 & 0.1 \\
\hline D1 & 1.1 & -3.3 & 0.6 & 1.3 \\
\hline D2 & 1.0 & -1.2 & 0.8 & 0.5 \\
\hline
\end{tabular}

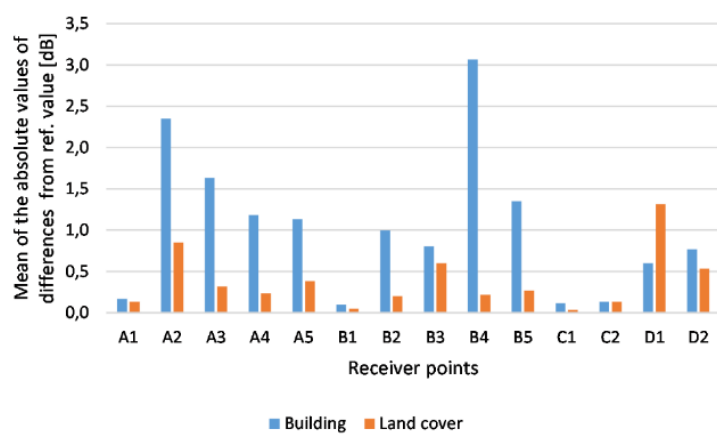

Figure 5. Mean of the absolute values of differences from building/land cover reference values in day-evening-night sound levels (Lden) in $d B$ at each receiver point

Concerning the building data, in the residential area there are significant differences at the receiver points located in the middle range of the propagation path. The highest values of maximum differences and mean differences were detected at point A3 $(-2.9 \mathrm{~dB}$ as maximum difference, building data source: $\mathrm{RPa}$, and 1,6 dB as mean difference) and at point B4 (-5.9 dB, building data source: $\mathrm{RPa}$, and 3,1 $\mathrm{dB})$. Smaller $L_{d e n}$ values than the building reference values are likely to be caused by assuming a constant value of $6 \mathrm{~m}$ for building height in test cases based on $\mathrm{RPa}$ building data source. This is an overestimation of the real building heights and the higher obstacles in the model result in lower sound levels. In the woodland, the differences are negligible, which follows from the lack of the buildings. In the industrial area, quite small differences were detected as well. This may be explained by that there are only a few buildings in that area; therefore, the differences in the building data sources do not influence the results significantly.

With respect to the land cover data, in the residential area much smaller differences can be noticed. The highest values of maximum differences and mean differences occur at point $\mathrm{A} 2(-1.2 \mathrm{~dB}$, land cover data source: CORINE, and $0,9 \mathrm{~dB})$ and at point B3 $(-1.5 \mathrm{~dB}$, land cover data source: CORINE, and $0,6 \mathrm{~dB})$. In the woodland the differences may be ignored (maximum differences are $-0.1 \mathrm{~dB}$ and $-0.3 \mathrm{~dB}$, land cover data source: CORINE, mean differences are $0,0 \mathrm{~dB}$ and $0,1 \mathrm{~dB}$ ), which can be explained by the quite similar land cover input data according to the different sources. The small negative deviation is likely to be caused by that the surface of the highway is considered as a separate land cover category according to the Urban Atlas ("Other roads and associated lands", Fig. 3a-b), which were taken into account as a reflective surface in the model. On the other hand, in the CORINE database, the area of the highway is covered by the class "Broad-leaved forest" (Fig. 2), which was counted as an absorbing surface in the model calculation. In the industrial area, there is a 
significant difference between the land cover data according to both the CORINE and the Urban Atlas (Fig. 2-3) databases. The latter shows a broader industrial area, which means a reflective surface with smaller $G$ value, while according to the CORINE database, a part of that area is defined as broadleaved forest, which is a more absorbing surface with higher $G$ value. This dissimilarity can cause that there is a considerable value of maximum difference at point $\mathrm{D} 1(-3.3 \mathrm{~dB}$, land cover source: CORINE) and also the mean difference is higher than it is at any other receiver points $(1,3 \mathrm{~dB})$.

According to the results shown in Table 3 and Fig. 5 the model calculation is more sensitive to the building data in the residential area. However, land cover data may have an important role in the industrial area.

Finally, the performance of each test case was estimated comparing its result to the reference value (result provided by the test case ORTO-UA+). The absolute value of the deviation of the results provided by each test case $\left(L_{d e n}[\mathrm{~dB}]\right)$ from the reference value at each receiver point is presented in Fig. 6-7. Fig. 6 and Fig. 7a show that in the residential area, the test cases using PRa as building data source provided the largest deviations. Within these test cases, the version using CORINE as the land cover data source performed the weakest (3.4 dB difference at point $\mathrm{A} 3$ and $6.3 \mathrm{~dB}$ at point B4). We note that the results provided by the test case ORTO-UA are almost equal to the reference value. This can be explained by the fact that in this part of the residential area hardly any extra reflective area has been identified; therefore, UA and UA+ data sources did not differ significantly (Fig. 3a-b). The deviations in the woodland are negligible (0-0.3 dB), as shown in Fig. 7b. As described above, this can be caused by the fact that there are no buildings in that area, and the land cover input data according to the different data sources are quite similar. In the industrial area, the highest deviation values at point $\mathrm{D} 1$ were provided by the test cases using CORINE land cover data (Fig. 7c). This can be explained by the different boundaries of land cover categories according to the CORINE database and the Urban Atlas in that area, as explained above.

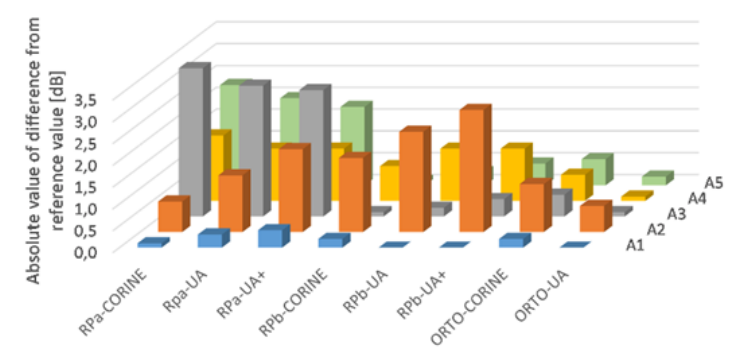

Figure 6. Absolute values of differences from reference values in day-evening-night sound levels (Lden) in $d B$ receiver points $A 1-A 5$

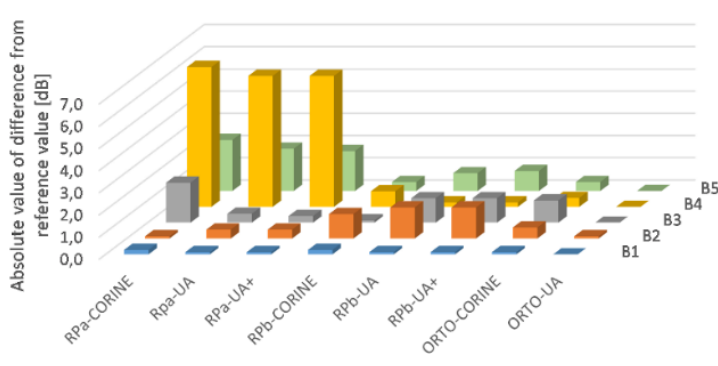

a)

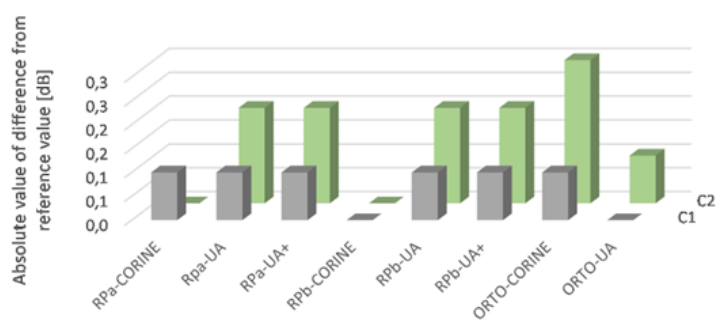

b)

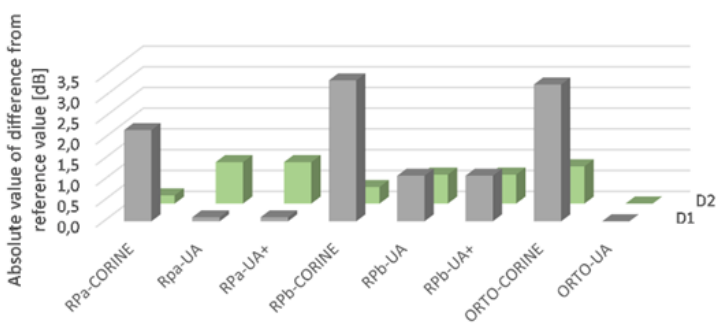

c)

Figure 7. Absolute values of differences from reference values in day-evening-night sound levels (Lden) in $d B$ a) receiver points $B 1-B 5 b)$ receiver points $C 1-C 2$ c) receiver points $D 1-D 2$

\section{CONCLUSIONS}

The accuracy of input data is a key issue in sound propagation model calculations. To perform the mandatory strategic noise mapping tasks, input data for quite large areas have been provided. As the financial sources and manpower required for this task are significant, it is essential to get to know the importance of input data accuracy for each influencing factor. The present study aimed to assess the effect of building and land cover input data accuracy on CNOSSOS-EU sound propagation model results.

The analysis shown in this article has limitations. It focused only on two influencing parameters, while the effects of other important factors (e. g. meteorological conditions) were not examined. Because of the lack of data for parameter $p$ in Hungary, default values were used in the model. As the same modelling conditions were used to determine the noise levels for each test cases to compare, it was assumed that this simplification did 
not influence the conclusions can be drawn from the comparison. However, the values of parameter $p$ for each part of the day at a regional scale in Hungary are expected to be determined in the framework of the CNOSSOS-EU adaptation project. Based on the result data, it could be expedient to perform further examinations on the effect of input data describing meteorological conditions.

An additional limitation is that the investigation was performed only in a given study site. Although an area with diverse land cover was selected, which includes residential, wooded and industrial areas, the conclusions drawn from the results of the analysis might be too specific. As in the residential area examined in the study there are only detached houses, the effect of other types of residential buildings (e. g. blocks of flats of different heights) cannot be assessed based on present analysis. However, horizontal and vertical expanse of the buildings can influence the propagation conditions in a significant way, mainly through multiple diffractions and reflections of the acoustic waves. Furthermore, the examined industrial area consists of only a few buildings of similar heights, but a more diverse complex of buildings may be more appropriate to assess the importance of input data for buildings. In the context of the study area, traffic flow data can be another influencing factor which could not been examined in the present study, as particular traffic flow values of a given road section were taken into account. Larger noise load caused by higher traffic flow (e. g. on a motorway) would result in a larger affected area with more buildings influencing the sound propagation. When evaluating the results, it should also be taken into account that the selected input data may reflect some typical Hungarian characteristics, which can be different from the conditions in other countries (e. g. in Western Europe). Therefore, further investigations need to be done in the future in various study sites, even in other countries. When selecting the study areas, it is recommended to select different types of residential and industrial areas, along with roads of different volume of traffic (e. g. highly urbanized, densely built-up areas with tall buildings and even a more complex road network; sparsely built-up areas along motorways; industrial areas with buildings of various sizes).

It is also important to highlight that the reference values are not considered as absolutely accurate results. They were regarded as the basis of the comparison, as they were the results of the test cases using the most detailed input data, which described the real conditions in the possibly most accurate way. In further investigations, reference values can be improved by using more accurate input data for buildings where it is available.

The results show that in the residential area, the range of $L_{d e n}$ values (the maximum difference amongst the results for the different test cases at each receiver point) can be quite large, especially in the middle of the propagation path, where differences between the different data sources exercise their effect strongly. Similarly, there is a significant range in the middle of the propagation path in the industrial area, where the boundaries of land cover classes according to the CORINE and the Urban Atlas databases do not correspond completely, besides the differences in the building databases. In the woodland, the differences amongst the test cases are negligible, as there are no buildings in that area and the land cover input data according to the different sources is quite similar. The quite large deviations amongst the results for the different test cases in the residential and industrial areas show that the accuracy of input data fundamentally influences the model results.

Taking into account all the limitations described above, it can be stated that as expected, in residential areas, the sound propagation model is more sensitive to the building data than to the land cover data. Therefore, it is recommended to use more detailed building input data (building footprints based on data sources at least at the accuracy level of orthophotos and building heights individually determined for each building instead of generalized building height levels) in those areas, while using a land cover database with higher resolution than CORINE land cover data does not provide significantly better results. Improving the land cover dataset by identifying extra absorptive areas does not have a significant effect on the results either. On the other hand, the influence of land cover input data on model results increases significantly in non-residential areas. To specify and extend the results on this issue, further investigations are recommended in areas with diverse land cover, considering that the Urban Atlas data source is only available for urban areas.

\section{AUTHOR CONTRIBUTIONS}

E. Balogh: Conceptualization, Experiments, Writing.

T. Schmelz: Theoretical analysis, Review and editing.

L. Orosz: Supervision, Review and editing.

\section{Disclosure STATEMENT}

The authors declare that they have no known competing financial interests or personal relationships that could have appeared to influence the work reported in this paper.

\section{ORCID}

E. Balogh http://orcid.org/0000-0002-9006-0351 


\section{REFERENCES}

[1] S. Kephalopoulos, M. Paviotti, F. AnfossoLédée, Common Noise Assessment Methods in Europe (CNOSSOS-EU). EUR 25379 EN. JRC72550. Luxembourg: Publications Office of the European Union (2012) https://doi.org/10.2788/31776

[2] Acoustics - Description and measurement of environmental noise - Part 2: Acquisition of data pertinent to land use, ISO 1996-2:1987 (1987).

https://www.iso.org/standard/6749.html

[3] Acoustics - outdoor noise - calculation of sound levels, NF S 31-133 (2011). https://infostore.saiglobal.com/enus/standards/nfs-31-133-201160554_saig_afnor_afnor_129788/

[4] E. Salomons, D. Van Maercke, et al., The Harmonoise sound propagation model, Acta Acustica United with Acustica 97 (2011) pp. 62-74. https://doi.org/10.3813/AAA.918387

[5] Acoustics - Attenuation of sound during propagation outdoors - Part 1: Calculation of the absorption of sound by the atmosphere, ISO 9613-1:1993(E) (1993). https://www.iso.org/standard/17426.html

[6] S. Kephalopoulos, M. Paviotti et al., Advances in the development of common noise assessment methods in Europe: The CNOSSOS-EU framework for strategic environmental noise mapping, Science of the Total Environment 482-483 (2014) pp. 400--410. https://doi.org/10.1016/j.scitotenv.2014.02.03 $\underline{1}$

[7] C. Foy, D. Ecotière, G. Dutilleux, Comparison of 3 engineering methods for outdoor sound propagation, in: 40. Jahrestagung für Akustik: DAGA, Oldenburg, 2014, pp. 828-829. https://pub.degaakustik.de/DAGA_2014/data/articles/000456. pdf

[8] E. Salomons, A. Eisses, Investigations of the Cnossos sound propagation model, in: 11th European Congress and Exposition on Noise Control Engineering: Euronoise 2018, European Acoustics Association, Crete, 2018, pp. 1253-1260.

https://www.euronoise2018.eu/docs/papers/21 2 Euronoise2018.pdf

[9] A. Kok, Refining the CNOSSOS-EU calculation method for environmental noise, in: 48th International Congress and Exhibition on Noise Control Engineering: INTERNOISE 2019, International Institute of Noise Control Engineering (I-INCE), Madrid, 2019, 1418. http://www.seaacustica.es/fileadmin/INTERNOISE 2019/Fc hrs/Proceedings/1418.pdf

[10] A. Kok, A. van Beek, Amendments for CNOSSOS-EU: Description of issues and proposed solutions, RIVM Letter report 2019-0023, National Institute for Public Health and the Environment, Bilthoven, The Netherlands (2019). https://doi.org/10.21945/RIVM-2019-0023

[11] K. Kumar, H. Ledoux et al., A Harmonized Data Model for Noise Simulation in the EU, ISPRS International Journal of GeoInformation 9 (2) (2020) 121. https://doi.org/10.3390/ijgi9020121

[12] D. W. Morley, K. de Hoogh et al., International scale implementation of the CNOSSOS-EU road traffic noise prediction model for epidemiological studies, Environmental Pollution 206 (2015) pp. 332341. https://doi.org/10.1016/j.envpol.2015.07.031

[13] F-E. Aballéa, J. Defrance et al., Sensitivities of outdoor sound propagation predictions to environmental input parameters, Noise Control Engineering Journal 55 (1) (2007) pp. 38-49. https://doi.org/10.3397/1.2402310

[14] J-P. Faulkner, E. Murphy et al., Towards a Good Practice Guide for Implementing CNOSSOS-EU in Ireland, EPA Research Report 383. Environmental Protection Agency, Wexford, Ireland (2021). https://www.epa.ie/publications/research/envir onment--health/Research_Report 383.pdf

[15] J. Khan, K. Kakosimos et al., The spatial relationship between traffic-related air pollution and noise in two Danish cities: Implications for health-related studies, Science of the Total Environment 726 (2020) 138577 https://doi.org/10.1016/j.scitotenv.2020.13857 $\underline{7}$

[16] KSH, 2011. ÉVI NÉPSZÁMLÁLÁS, 3. Területi adatok, 3.14 Pest megye [CENSUS 2011, 3. Spatial Data, 3. 14 Pest County], Hungarian Central Statistical Office, Budapest, Hungary (2013), in Hungarian. URL https://www.ksh.hu/docs/hun/xftp/idoszaki/ne psz2011/nepsz_03_14_2011.pdf 
[17] MK, Az országos közutak 2020. évre vonatkozó keresztmetszeti forgalma [Crosssectional flow data of national roads in 2020],

adatok/orszagos-kozutiHungarian Public Roads Ltd., Budapest,

Hungary (2021), in Hungarian

https://internet.kozut.hu/kozerdeku-

This article is an open access article distributed under the terms and conditions of the Creative Commons Attribution NonCommercial ( $C C B Y-N C$ 4.0) license. 